\title{
Three-Step Iterative Method for Solving Nonlinear Equations
}

\author{
I.A. Al-Subaihi \\ Department of Mathematics, Faculty of Science, Taibah University, Saudi Arabia \\ alsubaihi@hotmail.com
}

Copyright (C) 2015 Horizon Research Publishing All rights reserved.

\begin{abstract}
In this paper, a published algorithm is investigated that proposes a three-step iterative method for solving nonlinear equations. This method is considered to be efficient with third order of convergence and an improvement to previous methods. This paper proves that the order of convergence of the previous scheme is two, and the efficiency index is less than the corresponding Newton's method. In addition, the three-step iterative method of the scheme is implemented, and the previously published numerical results are found to be incorrect. Furthermore, this paper presents a new three-step iterative method with third order of convergence for solving nonlinear equations. The same numerical examples previously presented in literature are used in this study to correct those results and to illustrate the efficiency and performance of the new method.
\end{abstract}

Keywords Newton's method, Iterative methods, Nonlinear equations, Efficiency index, Order of convergence

\section{Introduction}

Finding zeros of nonlinear equations is a common scientific activity capable of answering questions about real-word phenomena. In recent years, many researchers have attempted to develop several iterative methods for solving nonlinear equations. Abbasbandy [1] and Chun [5] have proposed and studied several one-step and two-step iterative methods with higher orders of convergence using the Adomian decomposition method [2]. Noor and Noor [8] have considered another decomposition technique which does not involve derivatives of the Adomian polynomials; they used this decomposition to construct one-step, two-step and three-step iterative methods. J. Yun [10] proposed a three-step iterative method, which is a significant improvement of the method proposed by Noor and Noor [8]. Siyyam [9] derived and analyzed a new fourth-step iterative method with fifth order of convergence. Al-Subaihi and Alqarni [3] developed optimal three-step methods with eighth order of convergence. Al-Subaihi and Siyyam
[4] derived optimal iterative methods with eighth and sixteenth orders of convergence for solving nonlinear equations.

In Section 2, the main ideas of the decomposition technique by V. Daftardar-Gejji and H. Jafari [6] are outlined, and a new three-step iterative method for solving nonlinear equations is developed. The convergence analysis of the proposed method and the three-step iterative method proposed by Noor and Noor [8] are presented in Section 3. The same numerical examples presented in [8] are considered in Section 4 to show the performance and efficiency of the newly proposed scheme. Moreover, corrections to the results of [8] are also presented in this section. Conclusions and remarks are offered in Section 5.

\section{Iterative Algorithms}

Consider the nonlinear equation

$$
f(x)=0,
$$

assume that $f(x)$ has a simple root at $\alpha$, and $\gamma$ is an initial guess sufficiently close to $\alpha$. Rewrite equation (1) using the Taylor series as

$$
f(x)=f(\gamma)+(x-\gamma) f^{\prime}(\gamma)+\frac{(x-\gamma)^{2}}{2} f^{\prime \prime}(\gamma)=0
$$

where $\gamma$ is the initial approximation for a zero of (1).

Equation (1) can then be rewritten in the following equivalent form:

$$
x=c+N(x)
$$

where

$$
c=\gamma-\frac{f(\gamma)}{f^{\prime}(\gamma)}
$$

and

$$
N(x)=-\frac{(x-\gamma)^{2}}{2 f^{\prime}(\gamma)} f^{\prime \prime}(\gamma)
$$

Using the decomposition scheme of Daftardar-Gejji and Jafari [6], the solution of equation (3) ) is assumed to have the series form:

$$
x=\sum_{i=0}^{\infty} x_{i}
$$


The nonlinear operator $N(x)$ can be decomposed as

$N\left(\sum_{i=0}^{\infty} x_{i}\right)=N\left(x_{0}\right)+\sum_{i=1}^{\infty}\left(N\left(\sum_{j=0}^{i} x_{j}\right)-\left(N\left(\sum_{j=0}^{i-1} x_{j}\right)\right)\right.$

Combining Equations (3), (6) and (7),

$$
\begin{aligned}
x & =\sum_{i=0}^{\infty} x_{i} \\
& =c+N\left(x_{0}\right)+\sum_{i=1}^{\infty}\left(N\left(\sum_{j=0}^{i} x_{j}\right)-\left(N\left(\sum_{j=0}^{i-1} x_{j}\right)\right)\right)(8)
\end{aligned}
$$

Thus, the following scheme is determined:

$$
\begin{aligned}
x_{0}= & c \\
x_{1}= & N\left(x_{0}\right) \\
x_{2}= & N\left(x_{0}+x_{1}\right)-N\left(x_{0}\right), \\
\vdots & \\
x_{n+1}= & N\left(x_{0}+x_{1}+\ldots+x_{n}\right) \\
& -N\left(x_{0}+x_{1}+\ldots+x_{n-1}\right), n=0,1,2, \ldots
\end{aligned}
$$

Therefore,

$$
X_{n}=x_{0}+x_{1}+x_{2}+\ldots+x_{n}, \forall n=0,1,2, \ldots,
$$

denotes the $(n+1)$-term approximation of $x$, and hence, $x$ is approximated by

$$
x \approx X_{n}=x_{0}+x_{1}+\ldots+x_{n},
$$

for $n=0$,

$$
x \approx X_{0}=x_{0}=c=\gamma-\frac{f(\gamma)}{f^{\prime}(\gamma)} .
$$

This suggests the following one-step iterative method for solving the the nonlinear equation (1).

Algorithm 1 For a given $x_{0}$, compute the approximate solution $x_{n+1}$ by the iterative scheme:

$$
x_{n+1}=x_{n}-\frac{f\left(x_{n}\right)}{f^{\prime}\left(x_{n}\right)}, f^{\prime}\left(x_{n}\right) \neq 0, n=0,1,2, \ldots .
$$

This algorithm is well-known as Newton's method which has a second order of convergence.

From Equations (5), (9) and (10) with $n=1$,

$$
\begin{aligned}
x & \approx X_{1}=x_{0}+x_{1}=c+N\left(x_{0}\right) \\
& =\gamma-\frac{f(\gamma)}{f^{\prime}(\gamma)}-\frac{\left(x_{0}-\gamma\right)^{2}}{2 f^{\prime}(\gamma)} f^{\prime \prime}(\gamma)
\end{aligned}
$$

Using this relation, the following two-step iterative method for solving nonlinear equation (1) is suggested. Algorithm 2 For a given $x_{0}$, compute the approximate solution $x_{n+1}$ by the iterative scheme:

$$
\begin{gathered}
y_{n}=x_{n}-\frac{f\left(x_{n}\right)}{f^{\prime}\left(x_{n}\right)}, f^{\prime}\left(x_{n}\right) \neq 0 . \\
x_{n+1}=y_{n}-\frac{\left(y_{n}-x_{n}\right)^{2}}{2 f^{\prime}\left(x_{n}\right)} f^{\prime \prime}\left(x_{n}\right), \forall n=0,1,2, \ldots .
\end{gathered}
$$

This algorithm is called the two-step iterative method for solving nonlinear equation (1). It is worth mentioning that the above algorithm was obtained by Noor and Noor [8], and by Abbasbandy [1] using the Adomian decomposition method.

Again from Equations (5), (9) and (10) with $n=2$,

$$
\begin{aligned}
x & \approx X_{2}=x_{0}+x_{1}+x_{2}=c+N\left(x_{0}+x_{1}\right) \\
& =\gamma-\frac{f(\gamma)}{f^{\prime}(\gamma)}-\frac{\left(x_{0}+x_{1}-\gamma\right)^{2}}{2 f^{\prime}(\gamma)} f^{\prime \prime}(\gamma) .
\end{aligned}
$$

Using this relation, the following three-step iterative method for solving the nonlinear equation (1) is suggested.

Algorithm 3 For a given $x_{0}$, compute the approximate solution $x_{n+1}$ by the iterative scheme:

\section{Predictor Steps:}

$$
\begin{gathered}
y_{n}=x_{n}-\frac{f\left(x_{n}\right)}{f^{\prime}\left(x_{n}\right)}, f^{\prime}\left(x_{n}\right) \neq 0 \\
z_{n}=-\frac{\left(y_{n}-x_{n}\right)^{2}}{2 f^{\prime}\left(x_{n}\right)} f^{\prime \prime}\left(x_{n}\right),
\end{gathered}
$$

\section{Corrector Step:}

$$
\begin{aligned}
x_{n+1} & =x_{n}-\frac{f\left(x_{n}\right)}{f^{\prime}\left(x_{n}\right)}-\frac{\left(z_{n}+y_{n}-x_{n}\right)^{2}}{2 f^{\prime}\left(x_{n}\right)} f^{\prime \prime}\left(x_{n}\right) \\
& =y_{n}-\frac{\left(z_{n}+y_{n}-x_{n}\right)^{2}}{2 f^{\prime}\left(x_{n}\right)} f^{\prime \prime}\left(x_{n}\right) .
\end{aligned}
$$

Noor and Noor [8] derived a three-step iterative method for solving nonlinear equation (1), but the algorithm was quite different than algorithm 3 and is given as follows:

Algorithm 4 For a given $x_{0}$, compute the approximate solution $x_{n+1}$ by the iterative scheme:

\section{Predictor Steps:}

$$
\begin{gathered}
y_{n}=x_{n}-\frac{f\left(x_{n}\right)}{f^{\prime}\left(x_{n}\right)}, f^{\prime}\left(x_{n}\right) \neq 0 \\
z_{n}=-\frac{\left(y_{n}-x_{n}\right)^{2}}{2 f^{\prime}\left(x_{n}\right)} f^{\prime \prime}\left(x_{n}\right),
\end{gathered}
$$

\section{Corrector Step:}

$$
\begin{aligned}
x_{n+1}= & x_{n}-\frac{f\left(x_{n}\right)}{f^{\prime}\left(x_{n}\right)}-\frac{\left(y_{n}-x_{n}\right)^{2}}{2 f^{\prime}\left(x_{n}\right)} f^{\prime \prime}\left(x_{n}\right) \\
& -\frac{\left(z_{n}+y_{n}-x_{n}\right)^{2}}{2 f^{\prime}\left(x_{n}\right)} f^{\prime \prime}\left(x_{n}\right) \\
= & y_{n}+z_{n}-\frac{\left(z_{n}+y_{n}-x_{n}\right)^{2}}{2 f^{\prime}\left(x_{n}\right)} f^{\prime \prime}\left(x_{n}\right) .
\end{aligned}
$$

In the next section, algorithm 3 is shown with a cubic order of convergence while the Noor and Noor algorithm, Algorithm 4, has a quadratic convergence.

\section{Convergence Analysis}

The convergence analysis of the three-step iterative methods, Algorithms 3 and 4, for solving nonlinear equation (1) is established in this section. 
Theorem 1 Let $\alpha \in I$ be a simple zero of a sufficiently differentiable function $f: I \subseteq R \rightarrow R$ for an open interval $I$. If $x_{0}$ is sufficiently close to $\alpha$, then method (17), Algorithm 3, has a third order of convergence.

Proof Let $\alpha$ be a simple zero of (1) and $x_{n}=\alpha+e_{n}$. By the Taylor expansion,

$$
\begin{gathered}
f\left(x_{n}\right)=f^{\prime}(\alpha)\left(e_{n}+c_{2} e_{n}^{2}+c_{3} e_{n}^{3}\right)+\boldsymbol{O}\left(e_{n}^{4}\right), \\
f^{\prime}\left(x_{n}\right)=f^{\prime}(\alpha)\left(1+2 c_{2} e_{n}+3 c_{3} e_{n}^{2}\right)+\boldsymbol{O}\left(e_{n}^{3}\right), \\
f^{\prime \prime}\left(x_{n}\right)=f^{\prime}(\alpha)\left(2 c_{2}+6 c_{3} e_{n}\right)+\boldsymbol{O}\left(e_{n}^{2}\right),
\end{gathered}
$$

where $c_{k}=\frac{f^{(k)}(\alpha)}{k ! f^{\prime}(\alpha)}, k=2,3, \ldots$

Dividing (21) by (22), yields

$$
\frac{f\left(x_{n}\right)}{f^{\prime}\left(x_{n}\right)}=e_{n}-c_{2} e_{n}^{2}+2\left(c_{2}^{2}-c_{3}\right) e_{n}^{3}+\boldsymbol{O}\left(e_{n}^{4}\right) .
$$

From (15) and (24),

$$
y_{n}=\alpha+c_{2} e_{n}^{2}+2\left(c_{3}-c_{2}\right) e_{n}^{3}+\boldsymbol{O}\left(e_{n}^{4}\right) .
$$

Then,

$$
\left(y_{n}-x_{n}\right)^{2}=e_{n}^{2}-2 c_{2} e_{n}^{3}+\boldsymbol{O}\left(e_{n}^{4}\right) .
$$

From (22) and (23),

$$
\begin{aligned}
\frac{f^{\prime \prime}\left(x_{n}\right)}{2 f^{\prime}\left(x_{n}\right)}= & c_{2}+\left(3 c_{3}-2 c_{2}^{2}\right) e_{n}+\left(6 c_{4}-9 c_{2} c_{3}+4 c_{2}^{3}\right) \\
& \times e_{n}^{2}+\left(10 c_{5}-16 c_{2} c_{4}-9 c_{3}^{2}+24 c_{3} c_{2}^{2}\right. \\
& \left.-8 c_{2}^{4}\right) e_{n}^{3}+\boldsymbol{O}\left(e_{n}^{4}\right) .
\end{aligned}
$$

Substituting (26) and(27) into (16) and simplifying produces

$$
z_{n}=-c_{2} e_{n}^{2}+\left(4 c_{2}^{2}-3 c_{3}\right) e_{n}^{3}+\boldsymbol{O}\left(e_{n}^{4}\right) .
$$

Now from (25) and (28),

$$
z_{n}+y_{n}=\alpha+\left(2 c_{2}^{2}-c_{3}\right) e_{n}^{3}+\boldsymbol{O}\left(e_{n}^{4}\right) .
$$

Then,

$$
\left(z_{n}+y_{n}-x_{n}\right)^{2}=e_{n}^{2}+\boldsymbol{O}\left(e_{n}^{4}\right) .
$$

Substituting (25),(27) and (30) in (17) and simplifying finds that

$$
\begin{aligned}
e_{n+1} & =x_{n+1}-\alpha \\
& =-c_{3} e_{n}^{3}+\boldsymbol{O}\left(e_{n}^{4}\right) .
\end{aligned}
$$

This indicates that the order of convergence of the method defined by (17) is at least three. This completes the proof.

Theorem 2 Let $\alpha \in I$ be a simple zero of a sufficiently differentiable function $f: I \subseteq R \rightarrow R$ for an open interval $I$. If $x_{0}$ is sufficiently close to $\alpha$, then the method (20), Algorithm 4, has second order of convergence.

Proof Let $\alpha$ be a simple zero of $f$ and $x_{n}=\alpha+e_{n}$. Substituting (25), (27), (28) and (30) in (20) and simplifying to get

$$
\begin{aligned}
e_{n+1} & =x_{n+1}-\alpha \\
& =-c_{2} e_{n}^{2}+\boldsymbol{O}\left(e_{n}^{3}\right) .
\end{aligned}
$$

Which indicates that the method defined by (20) is of second-order. This completes the proof.

\section{Numerical examples}

In this section, the obtained theoretical results are confirmed by numerical experiments. Numerical test results are presented for the third-order method by comparison with famous iterative methods of different orders. The test functions and their roots, found up to the 17th decimal places, are as follows:

$$
\begin{aligned}
f_{1}(x)= & \sin ^{2} x-x^{2}+1, \alpha_{1}=1.40449164821534123 \\
f_{2}(x)= & x^{2}-e^{x}-3 x+2 \\
& \alpha_{2}=0.25753028543986076 \\
f_{3}(x)= & \cos x-x, \alpha_{3}=0.73908513321516064 \\
f_{4}(x)= & (x-1)^{3}-1, \alpha_{4}=2.0 \\
f_{5}(x)= & x^{3}-10, \alpha_{5}=2.15443469003188372 \\
f_{6}(x)= & x e^{x^{2}}-\sin ^{2} x+3 \cos x+5 \\
& \alpha_{6}=-1.20764782713091893 \\
f_{7}(x)= & e^{x^{2}+7 x}-e^{30}, \alpha_{7}=3.0
\end{aligned}
$$

Some numerical test results are also presented for various iterative schemes in Table 1 and are compared with the Newton method (NM) and the method of Abbasbandy [1] (AM) defined by

$$
x_{n+1}=y_{n}-\frac{f^{2}\left(x_{n}\right) f^{\prime \prime}\left(x_{n}\right)}{2 f^{\prime}\left(x_{n}\right)}-\frac{f^{3}\left(x_{n}\right) f^{\prime \prime \prime}\left(x_{n}\right)}{6 f^{\prime 4}\left(x_{n}\right)},
$$

the method of Homeier [7] (HM) defined by

$$
x_{n+1}=x_{n}-\frac{f\left(x_{n}\right)}{2}\left(\frac{1}{f^{\prime}\left(x_{n}\right)}+\frac{1}{f^{\prime}\left(y_{n}\right)}\right),
$$

the methods of Chun [5] (CM1) and (CM2) defined by

$$
x_{n+1}=y_{n}-2 \frac{f\left(y_{n}\right)}{f^{\prime}(x)}+\frac{f\left(y_{n}\right) f^{\prime}\left(y_{n}\right)}{f^{\prime 2}\left(x_{n}\right)},
$$

and

$$
x_{n+1}=y_{n}-\frac{f\left(y_{n}\right)}{f^{\prime}(x)},
$$

the method of Noor and Noor [8], (20) (NNM), and the new method, (17) (SM). All of the above methods have been implemented in this study.

All computations were completed using MATLAB 7 by using 100 digit floating arithmetic $(\mathrm{VPA}=100)$. The criteria

$$
\left|x_{n+1}-x_{n}\right|<\delta_{1},\left|f\left(x_{n+1}\right)\right|<\delta_{2},
$$

are used for stopping the computer program. Table 1 displays the number of iterations (IT), where the second number is the (IT) of [8]. Furthermore, the number of function evaluations (NFE) are required such that the stopping criteria $\delta_{1}$ and $\delta_{2}$ are less than $10^{-15}$ and the value of $\left|f\left(x_{*}\right)\right|$ is sufficient after the required iterations. Moreover, the computational order of convergence (COC) are displayed and approximated using formula [11]

$$
\rho=\frac{\ln \left|\left(x_{n+1}-\alpha\right) /\left(x_{n}-\alpha\right)\right|}{\ln \left|\left(x_{n}-\alpha\right) /\left(x_{n-1}-\alpha\right)\right|} .
$$


Table 1. Comparison of the various iterative schemes and the Newton method.

\begin{tabular}{|c|c|c|c|c|c|c|c|}
\hline & NM & $\mathrm{AM}$ & HM & CM1 & CM2 & NNM & SM \\
\hline \multicolumn{8}{|c|}{$f_{1}(x), x_{0}=1$} \\
\hline IT & 7,7 & 5,5 & 4,4 & 5,5 & 17 & 8,6 & 5 \\
\hline $\mathrm{COC}$ & 2.00 & 3.00 & 3.01 & 3.95 & 3.00 & 2.00 & 3.00 \\
\hline $\mathrm{NFE}$ & 14 & 20 & 12 & 20 & 51 & 15 & \\
\hline$\left|f\left(x_{*}\right)\right|$ & $-.1045 \mathrm{e}-49$ & $.3950 \mathrm{e}-61$ & $-.5402 \mathrm{e}-61$ & $-.1769 \mathrm{e}-66$ & $-.2620 \mathrm{e}-60$ & $.3482 \mathrm{e}-52$ & $.2493 \mathrm{e}-85$ \\
\hline$\delta_{1}$ & $.7328 \mathrm{e}-25$ & $.2473 \mathrm{e}-20$ & $.7918 \mathrm{e}-20$ & $.1312 \mathrm{e}-16$ & $.4413 \mathrm{e}-20$ & $.4231 \mathrm{e}-26$ & $.4856 \mathrm{e}-28$ \\
\hline$\delta_{2}$ & $.1819 \mathrm{e}-24$ & $.6138 \mathrm{e}-20$ & $.1966 \mathrm{e}-19$ & $.3257 \mathrm{e}-16$ & $.1096 \mathrm{e}-19$ & $.1050 \mathrm{e}-25$ & $.1206 \mathrm{e}-27$ \\
\hline \multicolumn{8}{|c|}{$f_{2}(x), x_{0}=2$} \\
\hline IT & 6,6 & 5,5 & 4,5 & 4,4 & 4 & 7,5 & 5 \\
\hline $\mathrm{COC}$ & 2.00 & 3.00 & 3.00 & 3.98 & 3.00 & 2.00 & 3.00 \\
\hline $\mathrm{NFE}$ & 12 & 20 & 12 & 16 & 15 & 21 & 15 \\
\hline$\left|f\left(x_{*}\right)\right|$ & $.2926 \mathrm{e}-54$ & $.3048 \mathrm{e}-92$ & $-.3525 \mathrm{e}-41$ & $-.1 \mathrm{e}-98$ & $-.1219 \mathrm{e}-40$ & $-.3608 \mathrm{e}-59$ & $.1198 \mathrm{e}-71$ \\
\hline$\delta_{1}$ & $.9103 \mathrm{e}-27$ & $.2028 \mathrm{e}-30$ & $.3198 \mathrm{e}-13$ & $.9463 \mathrm{e}-28$ & $.5695 \mathrm{e}-13$ & $.3196 \mathrm{e}-29$ & $.1771 \mathrm{e}-23$ \\
\hline$\delta_{2}$ & $.3440 \mathrm{e}-26$ & $.7665 \mathrm{e}-30$ & $.1208 \mathrm{e}-12$ & $.3576 \mathrm{e}-27$ & $.2152 \mathrm{e}-12$ & $.1208 \mathrm{e}-28$ & $.6693 \mathrm{e}-23$ \\
\hline \multicolumn{8}{|c|}{$f_{3}(x), x_{0}=1.7$} \\
\hline IT & 6,5 & 5,4 & 4,4 & 4,4 & 4 & 6,4 & 5 \\
\hline $\mathrm{COC}$ & 2.00 & 3.00 & 3.00 & 4.00 & 3.00 & 2.00 & 3.00 \\
\hline NFE & 12 & 20 & 12 & 16 & 15 & 18 & 15 \\
\hline$\left|f\left(x_{*}\right)\right|$ & $-.5447 \mathrm{e}-64$ & $-.590 \mathrm{e}-97$ & $-.5022 \mathrm{e}-58$ & $1 e-99$ & $-.8746 \mathrm{e}-72$ & $.6227 \mathrm{e}-54$ & $-.1 \mathrm{e}-99$ \\
\hline$\delta_{1}$ & $.1214 \mathrm{e}-31$ & $.5339 \mathrm{e}-32$ & $.9636 \mathrm{e}-19$ & $.1867 \mathrm{e}-52$ & $.1750 \mathrm{e}-23$ & $.1298 \mathrm{e}-26$ & $.4043 \mathrm{e}-46$ \\
\hline$\delta_{2}$ & $.2032 \mathrm{e}-31$ & $.8935 \mathrm{e}-32$ & $.1613 \mathrm{e}-18$ & $.3125 \mathrm{e}-52$ & $.2929 \mathrm{e}-23$ & $.2172 \mathrm{e}-26$ & $.6766 \mathrm{e}-46$ \\
\hline \multicolumn{8}{|c|}{$f_{4}(x), x_{0}=3.5$} \\
\hline IT & 8,8 & 6,5 & 5,5 & 5,5 & 6 & 6,4 & 5 \\
\hline $\mathrm{COC}$ & 2.00 & 3.00 & 3.00 & 3.99 & 3.00 & 2.00 & 3.00 \\
\hline NFE & 16 & 24 & 15 & 20 & 18 & 18 & 15 \\
\hline$\left|f\left(x_{*}\right)\right|$ & $.2057 \mathrm{e}-41$ & 0 & $.1565 \mathrm{e}-71$ & $.8483 \mathrm{e}-93$ & $.3722 \mathrm{e}-82$ & $-.6052 \mathrm{e}-40$ & $-.4099 \mathrm{e}-70$ \\
\hline$\delta_{1}$ & $.8280 \mathrm{e}-21$ & $.7505 \mathrm{e}-34$ & $.1463 \mathrm{e}-23$ & $.2742 \mathrm{e}-23$ & $.1837 \mathrm{e}-27$ & $.4491 \mathrm{e}-20$ & $.3448 \mathrm{e}-23$ \\
\hline$\delta_{2}$ & $.2484 \mathrm{e}-20$ & $.2502 \mathrm{e}-34$ & $.4389 \mathrm{e}-23$ & $.8227 \mathrm{e}-23$ & $.5512 \mathrm{e}-27$ & $.1347 \mathrm{e}-19$ & $.1034 \mathrm{e}-22$ \\
\hline \multicolumn{8}{|c|}{$f_{5}(x), x_{0}=1.5$} \\
\hline IT & 7,7 & 5,5 & 4,4 & 5,5 & 6 & 7,5 & 5 \\
\hline $\mathrm{COC}$ & 2.00 & 3.00 & 3.00 & 3.99 & 3.00 & 2.00 & 3.00 \\
\hline $\mathrm{NFE}$ & 14 & 20 & 12 & 20 & 18 & 21 & 15 \\
\hline$\left|f\left(x_{*}\right)\right|$ & $.2058 \mathrm{e}-53$ & $-.4294 \mathrm{e}-79$ & $.4699 \mathrm{e}-66$ & $.4262 \mathrm{e}-86$ & $-.1471 \mathrm{e}-94$ & $-.1367 \mathrm{e}-38$ & $-.1 \mathrm{e}-98$ \\
\hline$\delta_{1}$ & $.5643 \mathrm{e}-27$ & $.2206 \mathrm{e}-26$ & $.9795 \mathrm{e}-22$ & $.1573 \mathrm{e}-21$ & $.1349 \mathrm{e}-31$ & $.1454 \mathrm{e}-19$ & $.4700 \mathrm{e}-42$ \\
\hline$\delta_{2}$ & $.7858 \mathrm{e}-26$ & $.3072 \mathrm{e}-25$ & $.1364 \mathrm{e}-20$ & $.2190 \mathrm{e}-20]$ & $.1878 \mathrm{e}-30$ & $.2025 \mathrm{e}-18$ & $.6544 \mathrm{e}-41$ \\
\hline \multicolumn{8}{|c|}{$f_{6}(x), x_{0}=-2$} \\
\hline IT & 9,9 & 6,6 & 6,6 & 6,6 & 7 & 7,5 & 5 \\
\hline $\mathrm{COC}$ & 2.00 & 3.00 & 3.00 & 4.00 & 3.00 & 2.00 & 3.00 \\
\hline $\mathrm{NFE}$ & 18 & 24 & 12 & 24 & 21 & 21 & 15 \\
\hline$\left|f\left(x_{*}\right)\right|$ & $-.2269 \mathrm{e}-39$ & $-.2732 \mathrm{e}-87$ & $-.3448 \mathrm{e}-93$ & $-.5 e-98$ & $-.5 e-98$ & $.1839 \mathrm{e}-36$ & $.1455 \mathrm{e}-93$ \\
\hline$\delta_{1}$ & $.2728 \mathrm{e}-20$ & $.3024 \mathrm{e}-29$ & $.2569 \mathrm{e}-31$ & $.2154 \mathrm{e}-35$ & $.3339 \mathrm{e}-34$ & $.7764 \mathrm{e}-19$ & $.1529 \mathrm{e}-31$ \\
\hline$\delta_{2}$ & $.5539 \mathrm{e}-19$ & $.6141 \mathrm{e}-28$ & $.5217 \mathrm{e}-30$ & $.4374 \mathrm{e}-34$ & $6781 \mathrm{e}-33$ & $.1577 \mathrm{e}-17$ & $.3106 \mathrm{e}-30$ \\
\hline \multicolumn{8}{|c|}{$f_{7}(x), x_{0}=3.5$} \\
\hline IT & 13,13 & 8,7 & 8,8 & 8,8 & 10 & 8,6 & 7 \\
\hline $\mathrm{COC}$ & 2.00 & 3.00 & 3.00 & 3.99 & 3.00 & 2.00 & 3.00 \\
\hline $\mathrm{NFE}$ & 26 & 32 & 24 & 32 & 30 & 24 & 21 \\
\hline$\left|f\left(x_{*}\right)\right|$ & $.1517 \mathrm{e}-46$ & $.2815 \mathrm{e}-52$ & $.2730 \mathrm{e}-95$ & $.3750 \mathrm{e}-86$ & 0.0 & $-.4616 \mathrm{e}-36$ & $.1706 \mathrm{e}-86$ \\
\hline$\delta_{1}$ & $.4212 \mathrm{e}-24$ & $.4243 \mathrm{e}-18$ & $.2432 \mathrm{e}-32$ & $.2122 \mathrm{e}-22$ & $.3108 \mathrm{e}-45$ & $.7348 \mathrm{e}-19$ & $.1651 \mathrm{e}-29$ \\
\hline$\delta_{2}$ & $.5476 \mathrm{e}-23$ & $.5516 \mathrm{e}-17$ & $.3162 \mathrm{e}-31$ & $.2759 \mathrm{e}-21$ & $.4041 \mathrm{e}-44$ & $.9552 \mathrm{e}-18$ & $.2146 \mathrm{e}-28$ \\
\hline
\end{tabular}

Per iteration (IT), the method of (17) (SM) requires a single evaluation of the function and one evaluation of the first and second derivatives, $d=3$. It has been proved in the last section and shown in Table 1 that the method of (17) (SM) is of the third order, $p=3$. Thus, the informational efficiency $E=1$, and the efficiency index $I=1.442$, where $E$ is defined [1] as

$$
E=\frac{p}{d}
$$

and $I$ is defined as

$$
I=p^{\frac{1}{d}} .
$$

\section{Conclusions}

In this paper, a three-step iterative method for solving nonlinear equations (SM) has been developed. It has been proved that the method is of the third order of convergence. Moreover, it has also been proved that the order of convergence of the three-step iterative method proposed by Noor and Noor [8] is two. Based on calculations, the proposed method is also compared with various other iterative methods of the same order of convergence. The performance of the new method can be seen in Table 1. Furthermore, the results of the algorithm by Noor and Noor [8] are corrected. From Table 2 , it can easily be seen that the new method of (17) (SM) is better than the method of Noor and Noor (20) in the order of convergence. The informational efficiency, $E$ of (17), (SM) is greater than the Abbasbandy (33) (AM) and (20) the Noor and Noor (NNM). The efficiency index of the method of (SM) is equal to that of Homeier (34) (HM) and Chun (36) (CM2), and it is greater than 
Table 2. Comparison of the various iterative schemes and the Newton method.

\begin{tabular}{lccccccc}
\hline & NM & AM & HM & CM1 & CM2 & NNM & SM \\
\hline$p$ & 2 & 3 & 3 & 4 & 3 & 2 & 3 \\
$d$ & 2 & 4 & 3 & 4 & 3 & 3 & 3 \\
$E$ & 1 & 0.75 & 1 & 1 & 1 & 0.67 & 1 \\
$I$ & 1.414 & 1.316 & 1.442 & 1.414 & 1.442 & 1.260 & 1.442 \\
\hline
\end{tabular}

the other methods considered here. Furthermore, the method of Noor and Noor (20) has the smallest informational efficiency value $E$ and efficiency index $I$ value between all methods considered, which implies that their method is less efficient than the above methods.

\section{REFERENCES}

[1] S. Abbasbandy. Improving NewtonRaphson method for nonlinear equations by modified Adomian decomposition method, Appl. Math. Comput., 145, 887-893, 2003.

[2] G. Adomian. Nonlinear Stochastic Systems and Applications to Physics, Kluwer Academic Publishers, Dordrecht, 1989.

[3] I. A. Al-subaihi, A. J. Alqarni. Higher-Order Iterative Methods for Solving Nonlinear Equations, Life Science Journal, 11, 12, 85-91, 2014.

[4] I. A. Al-subaihi, H. I. Siyyam. Efficient Techniques for Constructing Optimal Iterative Methods with Eighth and Sixteenth Order of Convergence for Solving Nonlinear Equations, SYLWAN journal, 158, Issue. 5, 2014.

[5] C. Chun. Iterative method improving Newton's method by decomposition methods, Comput. Math. Appl., 50, 1559-1568, 2005.

[6] V. Daftardar-Gejji, H. Jafari. An iterative method for solving nonlinear functional equations, J. Math. Anal. Appl., 316, 753-763, 2006.

[7] H. H. H. Homeier. On Newton-type methods with cubic convergence, J. Comput. Appl. Math., 176, 425432, 2005 .

[8] M. A. Noor, K. I. Noor. Improved iterative methods for solving nonlinear equations, Appl. Math. Comput., 184, 270-275, 2007.

[9] H.I. Siyyam. An Iterative Method with Fifth-Order Convergence for Nonlinear Equations, Journal of Applied Mathematical Sciences, Vol. 3, No. 41, 2041-2053, 2009.

[10] J. H. Yun. A note on three-step iterative method for nonlinear equations, Appl. Math. Comput., 202, 401405, 2008.

[11] S. Weerakoon, G. I. Fernando. A variant of Newton's method with accelerated third-order convergence, Appl. Math. Lett., 17, 8, 87-93, 2000. 